\title{
Predictors of the development of takotsubo cardiomyopathy in aneurysmal subarachnoid hemorrhage and outcomes in patients with intra-aortic balloon pumps
}

\author{
Joshua S. Catapano, MD, Andrew F. Ducruet, MD, Fabio A. Frisoli, MD, Candice L. Nguyen, BS, \\ Christopher E. Louie, MB, MPH, Mohamed A. Labib, MD, CM, Jacob F. Baranoski, MD, \\ Tyler S. Cole, MD, Alexander C. Whiting, MD, Felipe C. Albuquerque, MD, and \\ Michael T. Lawton, MD
}

Department of Neurosurgery, Barrow Neurological Institute, St. Joseph's Hospital and Medical Center, Phoenix, Arizona

\begin{abstract}
OBJECTIVE Takotsubo cardiomyopathy (TC) in patients with aneurysmal subarachnoid hemorrhage (aSAH) is associated with high morbidity and mortality. Previous studies have shown that female patients presenting with a poor clinical grade are at the greatest risk for developing TC. Intra-aortic balloon pumps (IABPs) are known to support cardiac function in severe cases of TC, and they may aid in the treatment of vasospasm in these patients. In this study, the authors investigated risk factors for developing TC in the setting of aSAH and outcomes among patients requiring IABPs.
\end{abstract}

METHODS The authors retrospectively reviewed the records of 1096 patients who had presented to their institution with aSAH. Four hundred five of these patients were originally enrolled in the Barrow Ruptured Aneurysm Trial, and an additional 691 patients from a subsequent prospectively maintained aSAH database were analyzed. Medical records were reviewed for the presence of TC according to the modified Mayo Clinic criteria. Outcomes were determined at the last follow-up, with a poor outcome defined as a modified Rankin Scale (mRS) score $>2$.

RESULTS TC was identified in 26 patients with aSAH. Stepwise multivariate logistic regression analysis identified female sex (OR 8.2, $p=0.005)$, Hunt and Hess grade > III (OR 7.6, $p<0.001$ ), aneurysm size $>7 \mathrm{~mm}(\mathrm{OR} 3, p=0.011$ ), and clinical vasospasm (OR 2.9, $p=0.037$ ) as risk factors for developing TC in the setting of aSAH. TC patients, even with IABP placement, had higher rates of poor outcomes $(77 \%$ vs $47 \%$ with an $m R S$ score $>2, p=0.004)$ and mortality at the last follow-up $(27 \%$ vs $11 \%, p=0.018)$ than the non-TC patients. However, aggressive intra-arterial endovascular treatment for vasospasm was associated with good outcomes in the TC patients versus nonaggressive treatment $(100 \%$ with $m R S \leq 2$ at last follow-up vs $53 \%$ with $m R S>2, p=0.040$ ).

CONCLUSIONS TC after aSAH tends to occur in female patients with large aneurysms, poor clinical grades, and clinical vasospasm. These patients have significantly higher rates of poor neurological outcomes, even with the placement of an IABP. However, aggressive intra-arterial endovascular therapy in select patients with vasospasm may improve outcome. https://thejns.org/doi/abs/10.3171/2020.5.JNS20536

KEYWORDS aneurysmal subarachnoid; intra-aortic balloon pumps; takotsubo cardiomyopathy; vascular disorders

$\mathrm{T}$ AKOTSUBO cardiomyopathy (TC) is an infrequent complication of aneurysmal subarachnoid hemorrhage (aSAH), affecting roughly $1 \%$ of patients with the condition. ${ }^{1}$ Occurring predominantly in females with a poor neurological presentation, ${ }^{1-3} \mathrm{TC}$ is a reversible cardiomyopathy with unique diagnostic features, including 1) transient left ventricular midsegment dyskinesis, hypokinesis, or akinesis, with or without apical involvement; 2) regional wall motion abnormalities beyond the epicardial vascular distribution; 3) no obstructive coronary disease or rupture of a plaque on angiography; 4) elevated troponin levels or new electrocardiographic T-wave inversion or ST segment elevation or both; and 5) lack of pheochromocytoma or myocarditis. ${ }^{4,5}$ Although the pathogenesis of TC remains largely speculative, the cause of TC is thought to be catecholamine-induced cardiotoxicity. ${ }^{6}$ A catecholamine surge caused by the physical or emotional stress of a ruptured brain aneurysm activates the hypothalamus and

ABBREVIATIONS aSAH = aneurysmal subarachnoid hemorrhage; BRAT = Barrow Ruptured Aneurysm Trial; $\mathrm{HH}=$ Hunt and Hess; IABP = intra-aortic balloon pump; mRS $=$ modified Rankin Scale; TC = takotsubo cardiomyopathy.

SUBMITTED February 20, 2020. ACCEPTED May 18, 2020.

INCLUDE WHEN CITING Published online September 4, 2020; DOI: 10.3171/2020.5.JNS20536. 
causes downstream activation of the adrenal medulla (epinephrine release) as well as peripheral sympathetic nerves innervating the heart (norepinephrine release), causing increased afterload (alpha receptors) and hypercontraction of the left ventricle (beta receptors). These changes result in microvascular dysfunction and increased myocardial oxygen demand and cause left ventricle apex hypercontraction. Although some have speculated that coronary spasm or disease may contribute to some cases of TC, other studies have examined those patients who have undergone cardiac catheterization, and no evidence of coronary spasm or coronary artery disease was found. ${ }^{7-14}$ Furthermore, myocardial necrosis is not found in many of these patients, as troponin is elevated in less than half of patients with aSAH and TC. Regardless of the exact cause, this transient cardiac dysfunction poses a grave risk for patients with aSAH, who are often pharmacologically stimulated to elevated systolic blood pressure to treat vasospasm..${ }^{15}$ Accordingly, aSAH patients with TC have a higher risk of disability and death than those without TC. ${ }^{1}$

The optimal management protocol for aSAH patients with TC is uncertain. A few reports in the literature have supported the use of an intra-aortic balloon pump (IABP) to augment cardiac function and aid patients in vasospasm. ${ }^{2,16-22}$ However, IABP use in TC patients remains controversial because of the potential for associated complications such as sepsis, aortic dissection, aortic rupture, and major limb ischemia, and the supporting literature consists of only small case series and case reports. $2,23,24$ We have adopted an aggressive management approach, deploying IABPs in all aSAH patients with TC. In this review, we examine our experience, which is the most extensive reported to date. Although these TC patients face significant morbidity and mortality, we hypothesized that the use of IABPs would improve outcomes. We also examined the impact of aggressive endovascular management of vasospasm in these patients.

\section{Methods}

The institutional review board of St. Joseph's Hospital and Medical Center in Phoenix, Arizona, approved the study protocol, and informed consent was waived.

Two databases were retrospectively analyzed to identify all patients with a documented aSAH. The first database reviewed was from the Barrow Ruptured Aneurysm Trial (BRAT), a randomized controlled trial conducted from March 1, 2003, to January 31, 2007, that was designed to compare microsurgical clipping versus endovascular coiling in patients with aSAH. Subsequently, a prospectively collected database of all patients with aSAH who presented at our institution from January 1, 2007, to December 31,2017 , was examined. Both databases were reviewed for demographics, Hunt and Hess $(\mathrm{HH})$ grade, Fisher grade, presence of intraventricular hemorrhage, type of procedure performed, complications, cardiac dysfunction, aneurysm type, aneurysm size, aneurysm location, disposition after discharge, medication administration, placement of IABP, and neurological outcome.

Vasospasm was defined as a neurological change with either imaging or transcranial Doppler studies or both confirming the presence of intracerebral vascular constriction. Management of vasospasm was initiated when patients became clinically symptomatic with new neurological deficits during the 4- to 14-day period following aSAH. Imaging with CT was used to exclude other diagnoses that might explain the decline, such as hydrocephalus or hematoma. In addition, Doppler ultrasonography and $\mathrm{CT}$ angiography or catheter angiography were used to confirm the diagnosis of vasospasm. Medical therapy consisted of hypervolemia with intravenous fluids and hypertension with vasopressor agents. Endovascular therapy with arterial vasodilators (e.g., verapamil) with or without balloon angioplasty was added when symptomatic patients did not experience improvement despite reaching blood pressure targets. Our criterion for initiating therapy with an IABP was the failure of maximal medical and endovascular treatment.

All patients with cardiac dysfunction underwent chart review (including echocardiogram reports) for the presence of TC. TC was defined based on the modified Mayo Clinic criteria discussed in the Introduction. ${ }^{4}$ All patients with confirmed TC underwent placement of an IABP. Neurological outcomes were analyzed based on the modified Rankin Scale (mRS) score at the last follow-up, with an $\mathrm{mRS}$ score $>2$ defined as a poor outcome.

Statistical analysis was performed using SPSS Statistics Windows, version 26 (IBM Corp.). Percentages and frequencies were used to analyze demographics and clinical characteristics. A comparison of patient demographics and characteristics was performed via chi-square tests, and an independent two sample t-test was used for comparing interval data. A stepwise multivariate logistic regression analysis was used to identify variables that predict TC in aSAH patients. A p $<0.05$ was considered statistically significant.

\section{Results}

We analyzed the records of 1096 patients (405 from the BRAT) who had presented to our institution with aSAH during the study period. Of the 42 patients $(3.8 \%)$ diagnosed with reversible cardiac dysfunction, 26 (2.4\%) met the criteria for TC. All 26 TC patients underwent placement of an IABP. Tables 1 and 2 compare aSAH patients with and without TC. The TC patients had a significantly higher mean HH grade than those without TC (4.1 vs 2.8 , $\mathrm{p}<0.001$ ); they also had significantly higher mean mRS scores at the last follow-up (3.9 vs 2.7, p = 0.001), greater aneurysm diameter ( 9.3 vs $6.3 \mathrm{~mm}, \mathrm{p}<0.001)$, significantly different disposition (discharged home, $0 \%$ vs $38 \%$, p < 0.001 ), and significantly different Fisher grade (grade 4 , $92 \%$ vs $67 \%, \mathrm{p}<0.01$ ). A significantly greater number of aSAH patients with TC were found to have an mRS score $>2$ (OR 3.7, 95\% CI 1.5-9.3, p = 0.004), and mortality rates at the last follow-up for these patients were higher (OR $3.1,95 \%$ CI $1.3-7.6, p=0.018$ ) than those for the patients without TC. A significantly higher proportion of aSAH patients with TC were female (OR 10, 95\% CI 2.4-43, p < $0.001)$. Moreover, the TC patients were more likely to have an intraventricular hemorrhage (OR 4.0,95\% CI 1.2-13, p $=0.019)$, an HH grade > III (OR 9.5, 95\% CI 3.8-24, p < 
TABLE 1. Characteristics of aSAH patients with and without TC

\begin{tabular}{|c|c|c|c|}
\hline Characteristic & TC & No TC & $\mathrm{p}$ Value \\
\hline No. of patients & 26 & 1070 & \\
\hline Mean age in yrs & $54.5 \pm 13.7$ & $55.3 \pm 13.7$ & 0.748 \\
\hline Race & & & 0.648 \\
\hline White & $20(77)$ & $712(67)$ & \\
\hline Hispanic & $4(15)$ & $183(17)$ & \\
\hline Asian & $1(4)$ & $26(2)$ & \\
\hline African American & $0(0)$ & $59(6)$ & \\
\hline Native American & $1(4)$ & $38(4)$ & \\
\hline Other & $0(0)$ & $52(5)$ & \\
\hline Tobacco use & $9(35)$ & $535(50)$ & 0.164 \\
\hline Mean $\mathrm{HH}$ grade & $4.1 \pm 1.1$ & $2.8 \pm 1.1$ & $<0.001$ \\
\hline Mean no. of days to last FU & $201.4 \pm 457.5$ & $167 \pm 221$ & 0.453 \\
\hline Mean mRS score at last FU & $3.9 \pm 1.6$ & $2.7 \pm 1.9$ & 0.001 \\
\hline Mean aneurysm diameter in $\mathrm{mm}$ & $9.3 \pm 6.1$ & $6.3 \pm 3.7$ & $<0.001$ \\
\hline Fisher grade & & & 0.08 \\
\hline 2 & $0(0)$ & $98(9)$ & \\
\hline 3 & $2(8)$ & $238(22)$ & \\
\hline 4 & $24(92)$ & $734(69)$ & \\
\hline Disposition & & & 0.001 \\
\hline Home & $0(0)$ & $407(38)$ & \\
\hline Skilled nursing facility & $8(31)$ & $168(16)$ & \\
\hline Rehabilitation & $11(42)$ & $350(33)$ & \\
\hline Hospice & $1(4)$ & $43(4)$ & \\
\hline Died & $6(23)$ & $86(8)$ & \\
\hline Other & $0(0)$ & $16(1)$ & \\
\hline Aneurysm type & & & 0.566 \\
\hline Blister & $1(4)$ & $33(3)$ & \\
\hline Dissecting & $3(12)$ & $70(7)$ & \\
\hline Saccular & $22(85)$ & $925(86)$ & \\
\hline Fusiform & $0(0)$ & $42(4)$ & \\
\hline Aneurysm location & & & 0.294 \\
\hline Anterior cerebral artery & $0(0)$ & $47(4)$ & \\
\hline $\mathrm{ACoA}$ & $7(27)$ & $331(31)$ & \\
\hline Internal carotid artery & $0(0)$ & $104(10)$ & \\
\hline Middle cerebral artery & $5(19)$ & $156(15)$ & \\
\hline PCoA & $6(23)$ & $223(21)$ & \\
\hline Posterior cerebral artery & $1(4)$ & $19(2)$ & \\
\hline Basilar artery & $3(12)$ & $67(6)$ & \\
\hline Vertebral artery & $3(12)$ & $31(3)$ & \\
\hline PICA & $1(4)$ & $58(5)$ & \\
\hline Superior cerebellar artery & $0(0)$ & $17(2)$ & \\
\hline AICA & $0(0.0)$ & $2(0.2)$ & \\
\hline Anterior choroidal artery & $0(0)$ & $15(1.4)$ & \\
\hline
\end{tabular}

$\mathrm{ACOA}=$ anterior communicating artery; $\mathrm{AICA}=$ anterior inferior cerebellar artery; $\mathrm{FU}$ = follow-up; $\mathrm{PCoA}$ = posterior communicating artery; $\mathrm{PICA}=$ posterior inferior cerebellar artery.

Values are expressed as number (\%) or mean \pm standard deviation unless otherwise indicated. Boldface type indicates statistical significance.
TABLE 2. Risks, complications, and outcomes of aSAH patients with and without TC

\begin{tabular}{lccrc}
\hline Characteristic & $\begin{array}{c}\mathrm{TC}^{*} \\
(\mathrm{n}=26)\end{array}$ & $\begin{array}{c}\text { No TC } \\
(\mathrm{n}=1070)\end{array}$ & $\mathrm{p}$ Value & $\begin{array}{c}\text { OR } \\
(95 \% \mathrm{Cl})\end{array}$ \\
\hline $\begin{array}{l}\mathrm{mRS} \text { score }>2 \\
\text { at last FU }\end{array}$ & $20(77)$ & $504(47)$ & 0.004 & $3.7(1.5-9.3)$ \\
\hline Dead at last FU & $7(27)$ & $113(11)$ & $\mathbf{0 . 0 1 8}$ & $3.1(1.3-7.6)$ \\
\hline Female sex & $24(92)$ & $583(54)$ & $<0.001$ & $10(2.4-43)$ \\
\hline Age $>45$ yrs & $22(85)$ & $818(76)$ & 0.481 & $1.7(0.6-5.0)$ \\
\hline $\begin{array}{l}\text { Intraventricular } \\
\text { hemorrhage }\end{array}$ & $23(88)$ & $706(66)$ & $\mathbf{0 . 0 1 9}$ & $4.0(1.2-13)$ \\
\hline $\begin{array}{l}\text { HH grade }>\text { III } \\
\text { Vasospasm }\end{array}$ & $21(77)$ & $278(26)$ & $<0.001$ & $9.5(3.8-24)$ \\
\hline $\begin{array}{l}\text { Posterior circu- } \\
\text { lation aneurysm } \\
\text { rupture }\end{array}$ & $8(31.0)$ & $194(18)$ & 0.121 & $20(0.9-4.7)$ \\
\hline $\begin{array}{l}\text { Aneurysm size } \\
\geq 7 \text { mm }\end{array}$ & $17(65)$ & $377(35)$ & 0.003 & $3.5(1.5-7.9)$ \\
\hline $\begin{array}{l}\text { Treatment (mi- } \\
\text { crosurgery) }\end{array}$ & $13 / 24(54)$ & $658 / 1054(62)$ & 0.404 & $0.7(0.3-1.6)$ \\
\hline
\end{tabular}

Values expressed as number (\%) unless otherwise indicated. Boldface type indicates statistical significance.

* Two patients (8\%) with TC experienced a complication from the IABP (1 sepsis and 1 lower-extremity ischemia).

†All patients without recorded vasospasm in the TC group died within 72 hours of aSAH.

$\ddagger$ Eighteen patients did not undergo treatment due to nonsurvivable bleeds or clinical status.

0.001), a vasospasm (OR 2.9, CI 1.1-7.2, $\mathrm{p}=0.027)$, and an aneurysm $\geq 7 \mathrm{~mm}$ in diameter (OR $3.5,95 \%$ CI 1.5-7.9, $\mathrm{p}=0.003)$. Notably, 2 of the 26 TC patients (8\%) experienced a complication from the IABP: one became septic and the other experienced lower-extremity ischemia.

Predictors of TC in aSAH patients were analyzed via a stepwise multivariate logistic regression. The variables found to predict the development of TC in the final model were female sex (OR 8.2, 95\% CI 1.9-35, $\mathrm{p}=0.005)$, HH grade $>$ III $($ OR 7.6, 95\% CI 2.9-19, p < 0.001), aneurysm size $\geq 7 \mathrm{~mm}$ (OR 3.0, 95\% CI 1.3-7.1, $\mathrm{p}=0.011)$, and vasospasm (OR 2.9, 95\% CI 1.1-8.1, p = 0.037; Table 3).

Table 4 compares TC patients based on mRS score $>$ 2 or $\leq 2$ at the last follow-up. Endovascular intra-arterial infusion and/or angioplasty for vasospasm was significantly different between the two cohorts; all patients with an mRS score $\leq 2$ underwent treatment compared to $53 \%$ of patients with an mRS score $>2(p=0.040)$.

The aSAH patients with TC who had been treated with endovascular therapy for vasospasm $(n=14)$ were compared to those who did not receive such treatment $(n=7$; Table 5). Between these two cohorts, patient demographics, presentation $\mathrm{HH}$ grade, aneurysm type and location, disposition after discharge, use of vasopressors, and number of days with IABP did not differ significantly. However, all 7 patients who did not receive endovascular therapy had an mRS score $>2$ at follow-up, whereas 8 of 14 patients (57\%) who received endovascular therapy had an mRS score $>2$ at follow-up $(\mathrm{p}=0.040)$. 
TABLE 3. Predictors of TC in aSAH patients from stepwise logistic regression

\begin{tabular}{lcc}
\hline \multicolumn{1}{c}{ Variable Selected } & OR $(95 \% \mathrm{Cl})$ & p Value \\
\hline Female sex & $8.2(1.9-35)$ & $\mathbf{0 . 0 0 5}$ \\
\hline HH grade $>$ III & $7.6(2.9-19)$ & $<0.001$ \\
\hline Aneurysm size $\geq 7 \mathrm{~mm}$ & $3.0(1.3-7.1)$ & $\mathbf{0 . 0 1 1}$ \\
\hline Vasospasm & $2.9(1.1-8.1)$ & $\mathbf{0 . 0 3 7}$ \\
\hline
\end{tabular}

Boldface type indicates statistical significance.

Table $6^{1,15,25}$ reports the results from various studies of outcomes in aSAH patients with TC, excluding case reports. In all studies except the present study, no IABP was placed. Mortality rates for all studies were between $20 \%$ and $26 \%$.

\section{Discussion}

TC is associated with high morbidity and a risk of mortality of $26 \%$ during the initial hospitalization. ${ }^{1}$ aSAH patients with TC frequently experience clinical vasospasm, requiring pharmacologically elevated systolic blood pressures to counteract the vasospasm. However, TC diminishes cardiac output and limits therapeutic hypertension, placing patients at severe risk of complications from vasospasm. ${ }^{2}$ IABP placement in such patients provides cardiac support to elevate systolic blood pressures. ${ }^{2,16-22}$ However, the literature on IABP placement in patients with aSAH and TC is limited to small cases series and case reports. ${ }^{2,16-22}$ Our results reveal that even with IABP placement, aSAH patients with TC had significantly higher rates of mortality than those without TC. Similarly, Abd et al. found a mortality rate of $26 \%$ during hospitalization in a case series analyzing 19 patients with aSAH and TC but without an IABP. ${ }^{1}$ The authors concluded that factors associated with aSAH, rather than TC, likely contributed to the high mortality percentage, as prior studies demonstrated an in-hospital mortality rate of roughly $1 \%$ for all TC patients. ${ }^{1}$ Similarly, in an institutional review study, Talahma et al. reported a mortality rate of $22 \%$ among 18 patients with TC and aSAH, none of whom had received an IABP..$^{15}$ Inamasu and colleagues observed a $20 \%$ mortality rate in a retrospective review of 30 patients with TC and aSAH (none of whom had received an IABP). ${ }^{25}$ Our results are similar, as 6 of 26 patients (23\%) died during the initial hospitalization and $1(4 \%)$ died while in hospice care. Of the 6 patients who died during hospitalization, 5 died in the first 72 hours because of nonsurvivable neurological damage from the bleed, and 1 patient had care withdrawn on postbleed day 19 because of a continued poor neurological status. Although it is clear that aSAH patients with TC experience higher rates of mortality than those without TC, the impact of IABP warrants further investigation given these seemingly equivocal results.

Furthermore, our results demonstrate that aSAH patients with TC have significantly worse outcomes, as $77 \%$ of these patients had an mRS score $>2$ at the last followup compared to $47 \%$ of aSAH patients without TC. In contrast, another small case series by Talahma et al. ${ }^{15}$ of 18 aSAH patients with TC (and no IABP placed) showed that
TABLE 4. Risk factors for poor outcomes in aSAH patients with TC

\begin{tabular}{lccc}
\hline \multicolumn{1}{c}{ Characteristic } & $\begin{array}{c}\mathrm{mRS} \\
\text { Score } \leq 2\end{array}$ & $\begin{array}{c}\mathrm{mRS} \\
\text { Score }>2\end{array}$ & $\begin{array}{c}\mathrm{p} \\
\text { Value }\end{array}$ \\
\hline No. of patients & 6 & 20 & \\
\hline Age $>55$ yrs & $1(17)$ & $11(55)$ & 0.170 \\
\hline Female sex & $4(67)$ & $19(95)$ & 0.123 \\
\hline Intraventricular hemorrhage & $4(67)$ & $19(95)$ & 0.123 \\
\hline HH grade $>$ III & $4(67)$ & $16(80)$ & 0.596 \\
\hline Vasospasm & $6(100)$ & $15(75)$ & 0.298 \\
\hline Posterior circulation aneurysm & $1(17)$ & $7(35)$ & 0.628 \\
rupture & & & \\
\hline Aneurysm size $\geq 7$ mm & $4(67)$ & $13(65)$ & 0.940 \\
\hline Treatment (microsurgery) $(\mathrm{n}=24)$ & $2 / 6(33)$ & $11 / 18(61)$ & 0.357 \\
\hline Vasopressor administration & $6(100)$ & $20(100)$ & 0.99 \\
\hline Mean no. of days on vasopressors & $14 \pm 1.8$ & $13.8 \pm 6.1$ & 0.899 \\
\hline Mean no. of vasopressors & $4 \pm 0$ & $3.9 \pm 0.54$ & 0.806 \\
\hline Intra-arterial infusion for vaso- & $6 / 6(100)$ & $8 / 15(53) \ddagger$ & 0.040 \\
spasm \&/or angioplasty $(\mathrm{n}=21) \dagger$ & & & \\
\hline PBD that TC was diagnosed & $6 \pm 6$ & $5 \pm 3.8$ & 0.637 \\
\hline PBD that IABP was placed & $6.2 \pm 6.4$ & $5.3 \pm 4.4$ & 0.602 \\
\hline Mean no. of days w/ IABP & $5.7 \pm 2.1$ & $5.3 \pm 1.7$ & 0.702 \\
\hline$n$
\end{tabular}

$\mathrm{n}=$ number of patients; $\mathrm{PBD}=$ postbleed day.

Values are expressed as number (\%) or mean \pm standard deviation unless otherwise indicated. Boldface type indicates statistical significance.

* Five patients without a vasospasm recorded had died within 72 hours after aSAH.

† The 5 patients who died within 72 hours and did not have vasospasm recorded were excluded.

$\ddagger$ Three of the 7 patients did not receive vasospasm treatment due to hemodynamic instability. The other 4 patients did not undergo treatment because they were still responsive to medical therapy, and endovascular intervention was deemed unnecessary.

only $27 \%$ of patients had a poor outcome. However, that study defined a poor outcome as an mRS score $>3$ rather than $>2$. We believe an $\mathrm{mRS}>2$ is a more appropriate definition of a poor clinical outcome. In addition, an $\mathrm{mRS}$ range of scores of $0-2$ has been used in major stroke studies as an indication of a good outcome. ${ }^{26,27}$

All 6 patients with good outcomes $(\mathrm{mRS} \leq 2)$ in our study were treated aggressively for vasospasm using intra-arterial infusion of vasodilators or angioplasty or both. This treatment regimen was significantly different than that for the patients with a poor outcome (mRS > 3 ), $53 \%$ of whom received aggressive endovascular treatment. (Five patients did not have vasospasm recorded and had died within 72 hours as a result of the neurological injury caused by the bleed and thus were excluded from this analysis.) However, there remains controversy regarding intra-arterial treatment for vasospasm. Vasodilator infusion is thought to be short-lived, and angioplasty is technically challenging, with the potential for major complications, including vessel dissection or rupture. ${ }^{2,28}$ In a recent large meta-analysis, Venkatraman et al. ${ }^{29}$ found that endovascular treatment with intra-arterial vasodilators was associated with a high vascular response, improve- 
TABLE 5. TC patients treated with endovascular therapy for vasospasm compared to those without treatment

\begin{tabular}{|c|c|c|c|}
\hline Characteristic & $\begin{array}{l}\text { No Endovascular } \\
\text { Therapy }\end{array}$ & $\begin{array}{l}\text { Endovascular } \\
\text { Therapy }\end{array}$ & $\begin{array}{c}\mathrm{p} \\
\text { Value }\end{array}$ \\
\hline No. of patients & $7^{*}$ & 14 & \\
\hline Mean age in yrs & $59.7 \pm 12.7$ & $55.5 \pm 9.3$ & 0.397 \\
\hline Female sex & $7(100)$ & $12(86)$ & 0.533 \\
\hline Open treatment & $5(71)$ & $6(43)$ & 0.361 \\
\hline $\mathrm{HH}$ grade $>\mathrm{III}$ & $6(86)$ & $9(64)$ & 0.613 \\
\hline Aneurysm type & & & 0.347 \\
\hline Blister & $1(14)$ & $0(0)$ & \\
\hline Dissecting & $1(14)$ & $2(14)$ & \\
\hline Saccular & $5(71)$ & $12(86)$ & \\
\hline Aneurysm location & & & 0.292 \\
\hline $\mathrm{ACOA}$ & $1(14)$ & $4(29)$ & \\
\hline Middle cerebral artery & $2(29)$ & $2(14)$ & \\
\hline PCoA & $1(14)$ & $5(36)$ & \\
\hline Posterior cerebral artery & $0(0)$ & $1(7)$ & \\
\hline Basilar artery & $2(29)$ & $0(0)$ & \\
\hline Vertebral artery & $1(14)$ & $2(14)$ & \\
\hline Mean aneurysm size in $\mathrm{mm}$ & $8.6 \pm 5.4$ & $8.3 \pm 5.9$ & 0.918 \\
\hline Aneurysm size $\geq 7 \mathrm{~mm}$ & $5(71)$ & $8(57)$ & 0.656 \\
\hline Discharge location & & & 0.433 \\
\hline Skilled nursing facility & $3(43)$ & $5(36)$ & \\
\hline Rehabilitation & $3(43)$ & $8(57)$ & \\
\hline Hospice & $1(14)$ & $0(0)$ & \\
\hline Died & $0(0)$ & $1(7)$ & \\
\hline$m R S$ score $>2$ at FU & $7(100)$ & $8(57)$ & 0.040 \\
\hline $\begin{array}{l}\text { Mean no. of vasopressors } \\
\text { administered }\end{array}$ & $4.1 \pm 0.7$ & $3.9 \pm 0.3$ & 0.313 \\
\hline $\begin{array}{l}\text { Mean no. of days on vaso- } \\
\text { pressors }\end{array}$ & $16.6 \pm 5.6$ & $15 \pm 2.1$ & 0.335 \\
\hline Mean no. of days w/ IABP & $5.7 \pm 1.5$ & $5.8 \pm 1.8$ & 0.928 \\
\hline
\end{tabular}

Values are expressed as number (\%) or mean \pm standard deviation unless otherwise indicated. Boldface type indicates statistical significance.

* Five patients without endovascular therapy who died within the first 72 hours after presentation were excluded.

ment in neurological status, and mostly good outcomes. Similarly, in our study, when we compared aSAH patients with TC who had been treated with endovascular therapy for vasospasm to those who had not received endovascular treatment, we found that significantly fewer patients in the former group had a poor outcome at follow-up. Given that all patients who had not received endovascular therapy presented at follow-up with an mRS score $>2$, aggressive endovascular treatment would seem to confer improved outcomes. However, no other significant differences were demonstrated between these two cohorts. Therefore, our results support the notion that aggressive intra-arterial endovascular treatment improves outcomes in select aSAH patients with TC.

A number of studies have proposed that postmenopausal women with aSAH who have high $\mathrm{HH}$ and Fisher grades, as well as patients with vasospasm, are at an in-
TABLE 6. Inpatient mortality outcomes for TC reported in aSAH studies* $^{*}$

\begin{tabular}{lccc}
\hline \multicolumn{1}{c}{ Authors \& Year } & $\begin{array}{c}\text { No. of aSAH } \\
\text { Patients w/ TC }\end{array}$ & $\begin{array}{c}\text { No. of Patients } \\
\text { w/ IABP }\end{array}$ & Mortality \\
\hline Abd et al., 2014 & 19 & 0 & $5(26 \%)$ \\
\hline Talahma et al., 2016 & 18 & 0 & $4(22 \%)$ \\
\hline Inamasu et al., 2016 25 & 30 & 0 & $6(20 \%)$ \\
\hline Present study & 26 & 26 & $6(23 \%)$ \\
\hline
\end{tabular}

${ }^{*}$ Case reports were not included.

creased risk for TC..$^{1-4,30,31}$ Our data yielded similar results, showing that female sex, $\mathrm{HH}$ grade > III, and vasospasm were predictors of $\mathrm{TC}$ in the setting of aSAH. However, we also found an aneurysm size $\geq 7 \mathrm{~mm}$ to be a significant predictor for the development of TC. No prior studies have shown a relationship between aneurysm size and the development of cardiac dysfunction. Coincidentally, the recent SAFIRE grading scale showed aneurysm size to be a predictor of outcome in aSAH, with larger aneurysms associated with poorer outcomes. ${ }^{32}$

\section{Study Limitations}

The BRAT was a randomized controlled trial with prospective data collection; however, the present analysis is a combined retrospective review of the BRAT as well as a non-BRAT database. Consequently, any bias inherent to retrospective studies may be present. TC diagnosis was based on the modified Mayo Clinic criteria, ${ }^{4}$ but other criteria for the diagnosis of TC exist; if other criteria had been used, our findings might have been different. Another limitation was the relatively short median follow-up, particularly in the non-BRAT patient cohort. Finally, all patients with TC and aSAH had an IABP placed; therefore, an institutional comparison between patients who had an IABP placed and those who did not was not possible.

\section{Conclusions}

Among patients with aSAH, those with a poor clinical grade, female patients, patients with large ruptured aneurysms, and patients with vasospasm were found to be at higher risk for developing TC. Furthermore, aSAH patients with TC had significantly higher rates of poor neurological outcomes even with the placement of an IABP. However, aggressive intra-arterial endovascular therapy in select patients with vasospasm may mitigate the deleterious effect of the cardiac dysfunction and lead to meaningful recoveries.

\section{Acknowledgments}

We thank the Neuroscience Publications staff at Barrow Neurological Institute for help with manuscript preparation.

\section{References}

1. Abd TT, Hayek S, Cheng JW, et al. Incidence and clinical characteristics of takotsubo cardiomyopathy post-aneurysmal subarachnoid hemorrhage. Int J Cardiol. 2014;176(3):13621364. 
2. Ducruet AF, Albuquerque FC, Crowley RW, et al. Balloonpump counterpulsation for management of severe cardiac dysfunction after aneurysmal subarachnoid hemorrhage. World Neurosurg. 2013;80(6):e347-e352.

3. Lee VH, Connolly HM, Fulgham JR, et al. Tako-tsubo cardiomyopathy in aneurysmal subarachnoid hemorrhage: an underappreciated ventricular dysfunction. J Neurosurg. 2006; 105(2):264-270.

4. Prasad A, Lerman A, Rihal CS. Apical ballooning syndrome (Tako-Tsubo or stress cardiomyopathy): a mimic of acute myocardial infarction. Am Heart J. 2008;155(3):408-417.

5. Akashi YJ, Goldstein DS, Barbaro G, Ueyama T. Takotsubo cardiomyopathy: a new form of acute, reversible heart failure. Circulation. 2008;118(25):2754-2762.

6. Komamura K, Fukui M, Iwasaku T, et al. Takotsubo cardiomyopathy: pathophysiology, diagnosis and treatment. World J Cardiol. 2014;6(7):602-609.

7. Wittstein IS, Thiemann DR, Lima JA, et al. Neurohumoral features of myocardial stunning due to sudden emotional stress. N Engl J Med. 2005;352(6):539-548.

8. Tung P, Kopelnik A, Banki N, et al. Predictors of neurocardiogenic injury after subarachnoid hemorrhage. Stroke. 2004; 35(2):548-551.

9. Miss JC, Kopelnik A, Fisher LA, et al. Cardiac injury after subarachnoid hemorrhage is independent of the type of aneurysm therapy. Neurosurgery. 2004;55(6):1244-1251.

10. Tung PP, Olmsted E, Kopelnik A, et al. Plasma B-type natriuretic peptide levels are associated with early cardiac dysfunction after subarachnoid hemorrhage. Stroke. 2005;36(7): $1567-1569$.

11. Kopelnik A, Fisher L, Miss JC, et al. Prevalence and implications of diastolic dysfunction after subarachnoid hemorrhage. Neurocrit Care. 2005;3(2):132-138.

12. Banki NM, Kopelnik A, Dae MW, et al. Acute neurocardiogenic injury after subarachnoid hemorrhage. Circulation. 2005;112(21):3314-3319.

13. Banki N, Kopelnik A, Tung P, et al. Prospective analysis of prevalence, distribution, and rate of recovery of left ventricular systolic dysfunction in patients with subarachnoid hemorrhage. J Neurosurg. 2006;105(1):15-20.

14. Yarlagadda S, Rajendran P, Miss JC, et al. Cardiovascular predictors of in-patient mortality after subarachnoid hemorrhage. Neurocrit Care. 2006;5(2):102-107.

15. Talahma M, Alkhachroum AM, Alyahya M, et al. Takotsubo cardiomyopathy in aneurysmal subarachnoid hemorrhage: institutional experience and literature review. Clin Neurol Neurosurg. 2016;141:65-70.

16. Apostolides PJ, Greene KA, Zabramski JM, et al. Intra-aortic balloon pump counterpulsation in the management of concomitant cerebral vasospasm and cardiac failure after subarachnoid hemorrhage: technical case report. Neurosurgery. 1996;38(5):1056-1060.

17. Donaldson JW, Pritz MB. Myocardial stunning secondary to aneurysmal subarachnoid hemorrhage. Surg Neurol. 2001; 55(1):12-16.

18. Hoshi S, Suzuki KI, Shintaku I, et al. Two patients with N3 bladder cancer successfully treated by internal iliac arterial infusion chemotherapy and irradiation: case reports. Am J Clin Oncol. 2001;24(1):87-90.

19. Montessuit M, Chevalley C, King J, Faidutti B. The use of intra-aortic counterpulsation balloon for the treatment of cerebral vasospasm and edema. Surgery. 2000;127(2):230-233.

20. Nussbaum ES, Sebring LA, Ganz WF, Madison MT. Intraaortic balloon counterpulsation augments cerebral blood flow in the patient with cerebral vasospasm: a xenon-enhanced computed tomography study. Neurosurgery. 1998;42(1): 206-214.
21. Rosen CL, Sekhar LN, Duong DH. Use of intra-aortic balloon pump counterpulsation for refractory symptomatic vasospasm. Acta Neurochir (Wien). 2000;142(1):25-32.

22. Spann RG, Lang DA, Birch AA, et al. Intra-aortic balloon counterpulsation: augmentation of cerebral blood flow after aneurysmal subarachnoid haemorrhage. Acta Neurochir (Wien). 2001;143(2):115-123.

23. Lazaridis C, Pradilla G, Nyquist PA, Tamargo RJ. Intra-aortic balloon pump counterpulsation in the setting of subarachnoid hemorrhage, cerebral vasospasm, and neurogenic stress cardiomyopathy. Case report and review of the literature. Neurocrit Care. 2010;13(1):101-108.

24. Urban PM, Freedman RJ, Ohman EM, et al. In-hospital mortality associated with the use of intra-aortic balloon counterpulsation. Am J Cardiol. 2004;94(2):181-185.

25. Inamasu J, Ganaha T, Nakae S, et al. Therapeutic outcomes for patients with aneurysmal subarachnoid hemorrhage complicated by Takotsubo cardiomyopathy. Acta Neurochir (Wien). 2016;158(5):885-893.

26. Broderick JP, Palesch YY, Demchuk AM, et al. Endovascular therapy after intravenous t-PA versus t-PA alone for stroke. $N$ Engl J Med. 2013;368(10):893-903.

27. Furlan A, Higashida R, Wechsler L, et al. Intra-arterial prourokinase for acute ischemic stroke. The PROACT II study: a randomized controlled trial. Prolyse in Acute Cerebral Thromboembolism. JAMA. 1999;282(21):2003-2011.

28. Weant KA, Ramsey CN III, Cook AM. Role of intraarterial therapy for cerebral vasospasm secondary to aneurysmal subarachnoid hemorrhage. Pharmacotherapy. 2010;30(4): 405-417.

29. Venkatraman A, Khawaja AM, Gupta S, et al. Intra-arterial vasodilators for vasospasm following aneurysmal subarachnoid hemorrhage: a meta-analysis. J Neurointerv Surg. 2018; 10(4):380-387.

30. Connolly ES Jr, Rabinstein AA, Carhuapoma JR, et al. Guidelines for the management of aneurysmal subarachnoid hemorrhage: a guideline for healthcare professionals from the American Heart Association/American Stroke Association. Stroke. 2012;43(6):1711-1737.

31. Gianni M, Dentali F, Grandi AM, et al. Apical ballooning syndrome or takotsubo cardiomyopathy: a systematic review. Eur Heart J. 2006;27(13):1523-1529.

32. van Donkelaar CE, Bakker NA, Birks J, et al. Prediction of outcome after aneurysmal subarachnoid hemorrhage. Stroke. 2019;50(4):837-844.

\section{Disclosures}

The authors report no conflict of interest concerning the materials or methods used in this study or the findings specified in this paper.

\section{Author Contributions}

Conception and design: Catapano, Ducruet, Albuquerque, Lawton. Acquisition of data: Catapano, Nguyen, Louie, Labib, Baranoski. Analysis and interpretation of data: Catapano, Cole, Whiting. Drafting the article: Catapano, Louie. Critically revising the article: Lawton, Ducruet, Frisoli, Albuquerque. Reviewed submitted version of manuscript: Lawton. Statistical analysis: Catapano, Cole. Study supervision: Lawton.

\section{Correspondence}

Michael T. Lawton: c/o Neuroscience Publications, Barrow Neurological Institute, St. Joseph's Hospital and Medical Center, Phoenix, AZ.neuropub@barrowneuro.org. 